\title{
Longing for the country's good old days: National nostalgia, autochthony beliefs, and opposition to Muslim expressive rights
}

\author{
Anouk Smeekes*, Maykel Verkuyten and Borja Martinovic \\ ERCOMER, Utrecht University, the Netherlands
}

\begin{abstract}
Four studies tested the prediction that feelings of national nostalgia (i.e. nostalgia on the basis of one's national ingroup membership) result in more opposition towards expressive rights for Muslim immigrants, because they strengthen the belief that a place belongs to its original inhabitants, and that they are therefore more entitled (i.e. autochthony). Study I found that national nostalgia can be distinguished from personal nostalgia, and that national (rather than personal) nostalgia was related to more opposition to Muslim rights via stronger endorsement of autochthony. This latter result was replicated in another survey study (Study 2 ) and in an experiment (Study 3 ) in which national nostalgia was manipulated. Study 4 provided preliminary evidence that the salience of autochthony increases opposition to Muslim rights.
\end{abstract}

Scholars have argued that one of the consequences of the enhanced mobility of people is that they increasingly experience feelings of homelessness and nostalgia: '. . .there is widespread nostalgia for a condition of being at home in society, with oneself, and with the universe: for homes of the past that were socially homogeneous, communal, safe and secure' (Rapport \& Dawson, 1998, p. 31). In Western Europe, this nostalgic sentiment is linked to public discourses on immigration. Politicians claim that native majority members no longer feel at home in their own country, and that they increasingly long for a time when it was 'just us' (see Duyvendak, 2011). This is particularly blamed on the growing presence and visibility of Muslim immigrants, who tend to be perceived as having ways of life that are incompatible with that of natives (e.g. Gijsberts \& Lubbers, 2009; Sniderman \& Hagendoorn, 2007).

Historians, anthropologists and sociologists have described feelings of nostalgia that people may experience in relation to their group (e.g. Boym, 2001; Davis, 1979; Hewison, 1987). Although the consequences of nostalgia for individual lives have been examined, few social psychological studies have considered nostalgia in intergroup settings (but see Turner, Wildschut, \& Sedikides, 2012; Turner, Wildschut, Sedikides, \& Gheorghiu, 2013), and only recently attempts have been made to distinguish between personal and groupbased nostalgia (Wildschut, Bruder, Robertson, Tilburg, \& Sedikides, 2014). In this paper, we first examine whether feelings of nostalgia about one's nation (i.e. national nostalgia) can be distinguished from feelings of nostalgia in relation to one's individual biography (i.e. personal nostalgia). Second, we examine how these two forms of nostalgia inform native's attitudes towards Muslim immigrants. We specifically predicted that national

*Correspondence should be addressed to Anouk Smeekes, P.O. Box 80.140, 3508 TC Utrecht, the Netherlands (email: a.n.smeekes@uu.nl). 
(rather than personal) nostalgia increases the resistance to expressive rights of Muslim immigrants. The predicted reason for this was because national nostalgia encourages the belief in autochthony - the belief in entitlements of the first inhabitants ('owners') of a country - which has been shown to predict prejudice towards immigrants (Martinovic \& Verkuyten, 2013).

\section{Group-based nostalgia}

Historically, nostalgia was seen as a negative and maladaptive emotion characterized by feelings of loss and mourning. Yet, during the last decades it became increasingly understood as a positive emotion associated with happy memories of the past and a source of individual and social well-being (for reviews see Batcho, 2013; Sedikides, Wildschut, Arndt, \& Routledge, 2008). Nonetheless, recent research has argued that nostalgia may not always have positive consequences for individual functioning. For example, Iyer and Jetten (2011) demonstrated that, for individuals undergoing an important life transition, and who felt disconnected from their previous self, nostalgic longings impeded the ability to move on and face current challenges (see also Verplanken, 2012). Yet, like most work on nostalgia in social psychology, this research focused on the consequences of nostalgia for individual lives.

While there is an extensive body of research in social psychology on emotions experienced on behalf of one's group membership, such as group-based guilt (e.g. Branscombe \& Doosje, 2004), group-based nostalgia has been introduced in the field only recently (Wildschut et al., 2014). Based upon intergroup emotions theory (IET; Mackie, Devos, \& Smith, 2000) these researchers defined group-based nostalgia as 'the nostalgic reverie that is contingent upon thinking of oneself in terms of a particular social identity or as a member of a particular group' (p. 845). Following the four criteria of IET for identifying a group-level emotion, Wildschut et al. (2014) demonstrated that group-based nostalgia: (1) can be distinguished from personal nostalgia, (2) regulates attitudes and behaviours towards the ingroup, (3) has stronger implications for those high in social identification, and (4) is socially shared within a group.

We extend this work in two ways. First, we examine how group-based nostalgia affects intergroup rather than intragroup dynamics. Second, we focus on national nostalgia as a specific form of group-based nostalgia that is currently prevalent in West European public discourses on immigration and integration (Duyvendak, 2011). This nostalgic discourse refers to a combined sense of loss and longing for a (fondly remembered) national home of the past that was socially homogeneous and communal (Rapport \& Dawson, 1998).

\section{Group-based nostalgia and social categorization}

Theoretical work has proposed that group-based nostalgia typically emerges in times of social change, because it serves to repair a sense of identity discontinuity (Boym, 2001; Davis, 1979; Hewison, 1987). That is, group-based nostalgia is suggested to foster a renewed sense of social identity based on the awareness of shared past experiences in order to mend the lost one. Supporting this assertion, qualitative research has shown that after moving to a new site employees experienced discontinuity of their employee identity, which resulted in a shared experience of nostalgia for their old lost working environment (Milligan, 2003). Subsequently, this group-based nostalgia caused new social 
identity categories to arise: old employees saw the new employees as fundamentally different from them and felt that they did not share the same norms and values.

These findings suggest that group-based nostalgia fosters processes of social categorization. Longing for a shared past made a social identity based on these shared past experiences salient, which caused individuals to see and define themselves in terms of this 'old' group membership in relation to 'newcomers'. In line with selfcategorization theory (SCT; Turner, Hogg, Oakes, Reicher, \& Wetherell, 1987), the findings of Milligan (2003) indicate that salience of categorical boundaries was associated with self-stereotyping in terms of the shared norms, values and representations of the 'old' employee group. In this way, group-based nostalgia can trigger forms of social categorization and ingroup representation that define group membership criteria and mark group boundaries. Applying this reasoning to the context of native majority members living in culturally diverse settings, it is likely that national nostalgia fosters processes of social categorization in terms of the 'old' original inhabitants of the country versus 'newcomers' who have arrived later from elsewhere. This is subsequently likely to activate a national ingroup representation that marks group boundaries between natives and immigrants in order to regain a sense of national identity continuity. One ingroup representation that clearly marks these group boundaries and helps to regain a sense of continuity for native majority members is the notion of autochthony.

\section{Autochthony and prejudice}

Autochthony can be defined as a belief that assigns ownership and the related rights and entitlements to the group that is considered the first inhabitant of a territory (i.e. primooccupant; Geschiere, 2009). Just like first possession of an object is generally accepted as a basis for claiming ownership (Friedman, 2008), 'being here first' is considered a legitimate argument to claim ownership of the respective land (Geschiere, 2009). This means that groups who claim ownership on the basis of primo-occupancy feel entitled to decide on important collective matters regarding their country (Verkuyten, Sierksma, \& Thijs, 2014). Entitlement claims of native majority members on the basis of primo-occupancy have become an important notion in Western European debates on immigration (Ceuppens \& Geschiere, 2005; Geschiere, 2009). Anthropological research has described how the influx of immigrants and the accompanying diversification of districts and neighbourhoods cause natives to assert their 'rights to the ground' (Avila, 2004; Kasinitz \& Hillyard, 1995). This indicates that autochthony implies a special form of group ownership with an 'implicit call for excluding strangers' (Ceuppens \& Geschiere, 2005, p. 386).

Expressions of group-based nostalgia are found to be related to autochthony beliefs. For instance, ethnographic research by Kasinitz and Hillyard (1995) has described how nostalgia for communal solidarity among working-class White Americans helped them to claim that they, instead of the growing non-White population, represented the authentic voice of the community and were therefore entitled to assert ownership of the neighbourhood. This provides support for the idea that group-based nostalgia serves to regain a sense of identity continuity by reaffirming group boundaries in the context of increasing ethno-cultural diversity. Importantly, it highlights that, in such contexts, group-based nostalgia is related to a tendency to reassert group ownership and rights to 
the ground based on primo-occupancy. We expect a similar mechanism to be at work among native majority members in the Netherlands who live in a country that has become increasingly culturally diverse. Feeling nostalgic about their lost national home is likely to make natives want to restore group boundaries and entitlements based on their status as primo-occupants of the country.

Furthermore, just as the owner of an object can prevent others from using it (Friedman \& Ross, 2011), ownership of a territory by alleged primo-occupants goes together with the right to decide about group entitlements. According to the group position model (Blumer, 1958), a condition for prejudice to arise is that the ingroup must have a sense of proprietary claim over certain rights, statuses and resources which are denied to outgroups. As such, when native majority members are seen to have original rights to the ground this might leave less space for the public expression of immigrant cultures and identities. In many Western European countries, including the Netherlands, public expressions of Islam are perceived as corroding national identity and culture (Gijsberts \& Lubbers, 2009). We therefore expect that the stronger endorsement of autochthony resulting from feelings of national nostalgia will enhance natives' opposition to rights for Muslim immigrants to publicly confirm and express their identity.

\section{The present research}

We examined the consequences of national nostalgia for opposition to immigrant outgroups in the Dutch context. We hypothesized that national nostalgia is empirically distinct from personal nostalgia, and that only national nostalgia is related to stronger opposition towards Muslim expressive rights, via stronger endorsement of autochthony beliefs. These predictions were tested in four studies. Studies 1 and 2 were survey studies among samples of students and the native Dutch adult population, respectively. Studies 3 and 4 were experiments in which national nostalgia and autochthony were respectively manipulated.

\section{STUDY I}

Study 1 was designed to test whether personal nostalgia can be distinguished from national nostalgia, and how these two forms of nostalgia are related to autochthony beliefs and opposition to Muslim rights.

\section{Method}

\section{Participants}

This study was conducted among 122 Utrecht University students, and was part of a bigger data collection on perceptions of group history and intergroup relations. ${ }^{1}$ Students participated on a voluntary basis and the questionnaires were completed within a classroom setting. We only selected the participants who had two parents born in the Netherlands. This resulted in a total sample of 112 native Dutch participants $(77.7 \%$ women). The ages ranged between 18 and $44(M=20.40, S D=2.92)$.

\footnotetext{
' Data were collected within the framework of COST Action IS I 205 'Social psychological dynamics of historical representations in the enlarged European Union'.
} 


\section{Personal and national nostalgia}

The measures for personal and national nostalgia were based on a combination of two validated scales: Batcho's (1995) Nostalgia Inventory (NI) and the Southampton Nostalgia Scale (SNS; Routledge, Arndt, Sedikides, \& Wildschut, 2008). The reason for this combination is that NI focuses on missing specific aspects of the past, while SNS measures a more general tendency to feeling nostalgic. By using both scales we aimed to capture the multiple facets of nostalgia. Similar to NI, participants rated on a 5-point scale $(1=$ not at all, $5=$ very much) the extent to which they longed for six specific aspects of their past. The items are shown in Table 1 . The three items for personal nostalgia were taken from NI. For national nostalgia we adapted two items from NI to the national context (i.e. 'the way [Dutch] society was', 'the way [Dutch] people used to be') and designed one new item (i.e. 'The way the Dutch landscape (i.e. surroundings) looked like'). In addition, based on SNS, we included two items that assessed more general feelings of personal and national nostalgia. Using the same 5-point scale, participants responded to the following two items: 'How often do you bring to mind nostalgic experiences related to your childhood?', and 'How often do you bring to mind nostalgic experiences related to the way the Netherlands was in the past?'

\section{Autochthony}

We measured autochthony beliefs with a single item (based on Martinovic \& Verkuyten, 2013) using a 7-point scale ( 1 = strongly disagree, 7 = strongly agree): 'The Netherlands belongs more to native Dutch than to immigrant minorities, because native Dutch were here first'.

\section{Opposition to Muslim expressive rights}

We used five items (7-point scales; $\alpha=.75$ ) to measure participants' opposition to rights for Muslims to publicly express their identity. These items are based on previous Dutch studies (e.g. Smeekes, Verkuyten, \& Poppe, 2011, 2012). Participants indicated their agreement with Muslims in the Netherlands being allowed to: 'Practice the cultural traditions that are important to them', 'Show and express their identity in public', 'Raise their children in accordance with Muslim cultural traditions', 'Build mosques', and 'Found Islamic schools'.

Table I. Factor loadings for exploratory factor analysis of nostalgia items, Study I

\begin{tabular}{lccc}
\hline & Factor I & Factor 2 & Factor 3 \\
\hline My family house & & .67 & .90 \\
My childhood toys & & .79 & \\
My school & & .74 & \\
How often to you bring to mind nostalgic experiences & & \\
related to your childhood? & .82 & \\
The way Dutch people were & .90 & \\
The way Dutch society was & .70 & \\
The way the Dutch landscape (i.e. surroundings) & & \\
looked like \\
How often do you bring to mind nostalgic experiences \\
related to the way the Netherlands was in the past?
\end{tabular}




\section{Covariates}

Gender was a dummy variable and age was a continuous measure in years. Political orientation was measured with the well-known political self-placement scale (Jost, 2006), ranging from 1 (left) to 5 (right). One item assessed the extent to which participants identified with the Netherlands: 'How strongly do you feel Dutch?' This item was measured on a 10-point scale ranging from 1 (not at all) to 10 (very much).

\section{Results}

\section{Factor analysis}

We first performed exploratory factor analysis on all the nostalgia items with oblique rotation in SPSS. As shown in Table 1, a three factor structure emerged, in which personal and national nostalgia loaded on two different factors. The nostalgia item concerning one's family house formed a factor on its own, probably because many participating students were still living at their family house. We therefore omitted this item from further analysis. ${ }^{2}$ We computed a 3-item scale for personal nostalgia $(\alpha=.60)$ and a 4-item scale for national nostalgia $(\alpha=.80)$. Table 2 shows the descriptive findings for all variables, the bivariate correlations, and the partial correlations controlling for the covariates.

\section{Path model}

To examine our predictions we specified the path model in Figure 1 . We tested this model (in AMOS 21.0) using manifest variables, as the sample size was too small to test a structural equation model with latent variables (Kline, 2005). In this model, we included personal nostalgia as an additional predictor and treated age, gender, political orientation and national identification as covariates. The standardized paths and explained variances $\left(R^{2}\right)$ are shown in Figure 1. As expected, national (rather than personal) nostalgia

Table 2. Partial and non-partial correlations for all measures, Study I

\begin{tabular}{lcccccc}
\hline & $M$ & $S D$ & 1 & 2 & 3 & 4 \\
\hline I. Personal nostalgia & 2.51 & 0.70 & - & $.27^{* *}$ & .15 & .13 \\
2. National nostalgia & 1.79 & 0.71 & $.21^{*}$ & - & $.28^{* *}$ & .12 \\
3. Autochthony & 3.38 & 1.68 & .08 & $.23^{*}$ & - & $.29 * * *$ \\
4. Opposition to Muslim expressive rights & 3.03 & 0.83 & .04 & .04 & $.26^{* *}$ & - \\
Covariates & & & & & & \\
5. Gender & - & - & -.01 & -.07 & .05 & .02 \\
6. Age & 20.40 & 2.92 & $-.22^{*}$ & -.08 & -.18 & -.07 \\
7. Political orientation & 2.41 & 0.94 & $.30^{* *}$ & $.21^{*}$ & $.22^{*}$ & $.36^{* * *}$ \\
8. National identification & 7.59 & 1.65 & -.02 & .15 & .17 & .12 \\
\hline
\end{tabular}

Note. The correlations between the four core constructs are presented above the diagonal and were calculated without controlling for the covariates.

$* p<.05 ; * * p<.01 ; * * p<.001$.

${ }^{2}$ We also performed confirmatory factor analysis using AMOS 21.0 software, which showed that the items assessing personal and national nostalgia, and opposition to Muslim expressive rights, composed different factors. Results are available on request. 


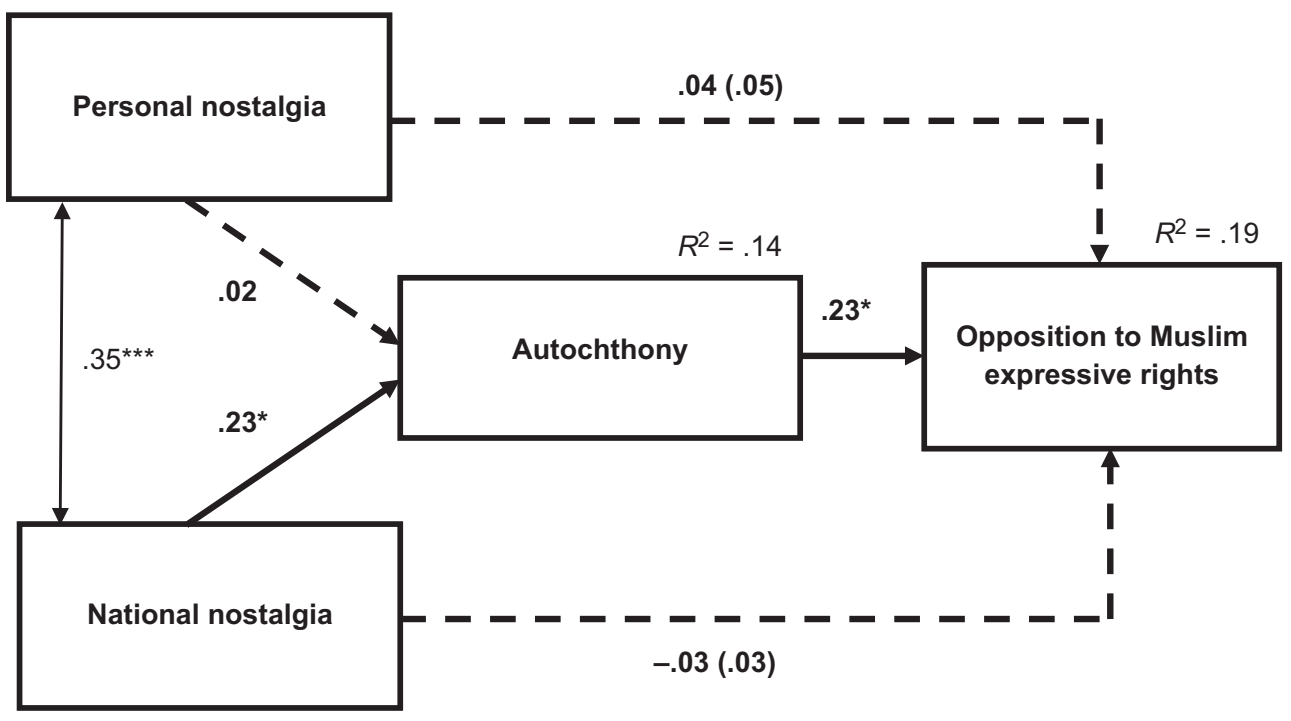

Figure I. Path model (Study I): influence of personal and national nostalgia on opposition to Muslim expressive rights, via autochthony (including national identification, age, gender, and political orientation as covariates). Note. Path coefficients are standardized estimates (marked in boldface), and the path coefficient in parenthesis reflects the total effect. Non-significant paths are shown as broken arrows. The model is saturated and hence the fit is perfect. $* p<.05 ; * * p<.001$.

significantly predicted autochthony beliefs, which were subsequently related to stronger opposition to Muslim expressive rights. ${ }^{3}$

There were no significant direct effects of the two forms of nostalgia on opposition. However, we tested the indirect effect of national nostalgia on opposition, via autochthony, because exogenous variables can exert an effect on endogenous variables in the absence of a direct relation between them (Hayes, 2009). This means that only the indirect effect needs to be significant in order to establish a connection between the two (Zhao, Lynch, \& Chen, 2010). We tested the indirect effect of national nostalgia using bootstrapping procedures in AMOS 21.0. We generated 5,000 bootstrap samples with replacement from the dataset $(N=112)$ and tested the model with these samples. The analysis revealed a significant indirect effect of national nostalgia, with a point estimate of .06 and a $95 \%$ bias-corrected confidence interval (BCCI) of .003-.134. This result shows that national nostalgia is indirectly related to stronger opposition to Muslim expressive rights, via a stronger endorsement of autochthony.

\section{STUDY 2}

The results of Study 1 demonstrate that personal nostalgia can be distinguished from national nostalgia, and that only the latter form is related to stronger endorsement of autochthony beliefs, which subsequently predict stronger opposition to Muslim expressive rights. In Study 2, we aimed to build on the findings of Study 1 in various ways. First, Study 1 was based on a student sample in which feelings of national nostalgia

\footnotetext{
${ }^{3}$ Of the covariates, only political orientation was a significant positive predictor of opposition.
} 
were quite low. We therefore tested in Study 2 whether the predicted effects could also be observed among a broader adult sample of the native Dutch population.

Second, in Study 1 we measured national nostalgia with a combination of items based on Batcho's (1995) NI and Routledge et al.'s (2008) SNS. We found that people who expressed nostalgia about a specific aspect of their national past also tended to long for the national past in general. This indicates that, although multifaceted, national nostalgia may be conceptualized and operationalized as a composite construct referring to feelings of nostalgia that people may experience on the basis of their national ingroup membership. Therefore, in Study 2, we designed a new composite measure for national nostalgia that more generally targeted feelings of nostalgia that people may feel for their country. This new measure also allowed us to assess whether a different and more general measure of national nostalgia yields similar results.

In addition, we measured autochthony beliefs and national identification with multiple items in Study 2, in order to be able to assess whether they are empirically distinct from national nostalgia and opposition to Muslim rights. In addition, Study 2 assessed whether national nostalgia is empirically distinct from other temporal understandings of national identity (i.e. perceived national identity continuity), and whether it remains a unique predictor when this variable is controlled for.

\section{Method}

\section{Participants and procedure}

This survey study was part of a larger online data collection among a representative sample $(N=933)$ of the native Dutch adult population. Participants received the questionnaire by means of an e-mail sent by TNS NIPO Consult. ${ }^{4}$ They were randomly assigned to six different versions of the questionnaire, and we only selected those who completed the version that contained the measures for the current study $(N=162)$. Respondents were drawn from a panel maintained by TNS NIPO Consult, and the characteristics of the panel and the sample closely match those of the general native Dutch population. Two respondents indicated that one of their parents had a non-native background and they were therefore excluded from the sample. This resulted in a sample of 160 native Dutch participants (47.5\% women). Ages ranged between 18 and $88(M=48.95, S D=17.19)$.

\section{Measures}

Except for national nostalgia and the background characteristics, all items were rated on a scale ranging from 1 (strongly disagree) to 7 (strongly agree).

\section{National nostalgia}

We designed four items to assess to what extent participants experienced national nostalgia $(\alpha=.90)$ : 'How often do you experience nostalgia when you think about the Netherlands of the past?', 'How often do you long for the good old days of the country?', 'How often do you long for the Netherlands of the past?', 'How often do you feel nostalgic

\footnotetext{
${ }^{4}$ For more information on TNS NIPO Consult, which is a consultancy company that conducts surveys and other studies among the Dutch population, see http://www.tns-nipo.com.
} 
when you hear Dutch songs from the past?' Items were rated on a scale ranging from 1 (very rarely) to 5 (very frequently).

\section{Autochthony}

We used the 4-item scale from Martinovic and Verkuyten (2013) to measure autochthony beliefs $(\alpha=.93)$. The items were: 'The original inhabitants of a country are more entitled than newcomers', 'Every country belongs to its original inhabitants', 'The original inhabitants of a country have the most right to define the rules of the game', and "We were here first", is an important principle for determining who decides on what happens in a country'.

\section{Opposition to Muslim expressive rights}

We used six items $(\alpha=.90)$ that were similar to the ones used in Study 1 to measure opposition to Muslim expressive rights. Items were reverse scored, so a higher score indicated more opposition. ${ }^{5}$

\section{Covariates}

We assessed the same background characteristics as in Study 1 (i.e. gender, age, and political orientation), and in addition included education (a scale ranging from 1 (primary education) to 8 (university degree)). Furthermore, we measured national identification with four items $(\alpha=.92)$. Two sample items are: 'I identify strongly with the Netherlands' and 'I feel really Dutch'. In addition, we included a measure of perceived cultural continuity (PCC), which was measured with five items $(\alpha=.93)$ developed by Sani $e t$ al. (2007). Two sample items are: 'Dutch people have passed on their traditions to different generations', and 'Shared Dutch values and beliefs of Dutch people have endurance across times'.

\section{Results}

\section{Confirmatory factor analyses}

We performed confirmatory factor analyses, in AMOS 21.0, to determine whether the items assessing national nostalgia, national identification, PCC, autochthony and opposition to Muslim expressive rights composed different factors. ${ }^{6}$ We compared the fit of a five-factor model to various four-factor models. Items were only allowed to load on the factor they were expected to indicate and no items were allowed to correlate. The results of the analyses are shown in Table 3. The proposed five-factor structure had a good fit to the data. The $z$-statistics obtained for all the factor loadings were significant $(p s<.001)$ and the standardized factor loadings were all above .62. Chi-square difference

\footnotetext{
${ }^{5}$ The number of items for measuring opposition to Muslim expressive rights varied between 4 and 6 across the four studies. The reason is that the different datasets used for the studies were all part of bigger data collections which sometimes restricted the number of items that could be included to measure a particular construct.

${ }^{6}$ As our data were part of a larger data collection, we were also able to test and demonstrate that autochthony is empirically distinct from the well-known multicultural ideology scale (e.g. Arends-Tóth \& Van de Vijver, 2003). In addition, we also ran additional analysis of our mediation model (see Figure 2) with multicultural ideology as a covariate and this yielded similar results. Results are available on request.
} 
Table 3. Fit indices of models tested in confirmatory factor analyses, Study 2

\begin{tabular}{lccccc}
\hline & $\chi^{2}(\mathrm{df})$ & $\Delta \chi^{2}$ & CFI & RMSEA & AIC \\
\hline 5-Factors & $336.12(220)^{* * * *}$ & & .96 & .06 & 448.12 \\
$\begin{array}{c}\text { 4-Factor model I } \\
\text { (nostalgia with identification) }\end{array}$ & $821.38(224)^{* * *}$ & $485.26^{* * * *}$ & .79 & .13 & 925.38 \\
$\begin{array}{c}\text { 4-Factor model 2 } \\
\text { (nostalgia with PCC) }\end{array}$ & $856.20(224)^{* * *}$ & $520.08^{* * * *}$ & .78 & .13 & 960.20 \\
$\begin{array}{c}\text { 4-Factor model 3 } \\
\text { (nostalgia with autochthony) }\end{array}$ & $759.26(224)^{* * *}$ & $423.14^{* * * *}$ & .81 & .12 & 863.26 \\
$\begin{array}{c}\text { 4-Factor model 4 } \\
\text { (nostalgia with opposition) }\end{array}$ & $736.06(224)^{* * *}$ & $399.94^{* * * *}$ & .82 & .12 & 840.06 \\
$\begin{array}{c}\text { 4-Factor model 5 } \\
\text { (autochthony with opposition) }\end{array}$ & $724.95(224)^{* * * *}$ & $388.83^{* * * *}$ & .83 & .12 & 828.95 \\
\hline
\end{tabular}

Note. CFI = Comparative Fit Index; RMSEA = root mean square error of approximation; $\mathrm{AIC}=$ Akaike Information Criterion.

$* * * p<.001$.

tests indicated that the proposed five-factor structure fit the data better than any of the alternative models, which indicates that these are all separate constructs (see Table 4 for descriptive findings, bivariate correlations, and partial correlations controlling for the covariates). ${ }^{7}$

\section{Structural equation modelling}

We conducted structural equation modelling (in AMOS 21.0) using latent variables for the three core constructs, which provides more reliable results than path analyses using only manifest variables (Kline, 2005). We included education, political orientation, national identification, and PCC (both latent variables) as predictors of autochthony and opposition to Muslim expressive rights in the model. ${ }^{8}$ To test our predictions we specified the model in Figure 2, which shows the standardized paths, explained variance $\left(R^{2}\right)$ and model fit statistics. These analyses revealed that national nostalgia significantly and positively predicted autochthony beliefs and opposition to Muslim expressive rights. Moreover, autochthony was a significant positive predictor of opposition.?

We subsequently tested the indirect effect of national nostalgia on opposition, via autochthony, using bootstrapping procedures (5,000 samples) and controlling for the covariates. The analysis revealed a significant indirect effect of national nostalgia, with a standardized point estimate of .12 and a 95\% BCCI of .055-.212. The main effect of national nostalgia on opposition remained significant when autochthony was included in the model (see Figure 2), which indicates that part of the relationship was explained by autochthony (i.e. partial mediation).

\footnotetext{
${ }^{7}$ We also performed exploratory factor analysis in SPSS including all items of national nostalgia, autochthony, opposition, PCC, and national identification. Results showed a clear five-factor structure where the loadings were as expected. We also examined whether the associations of national nostalgia with autochthony and opposition were moderated by age, but this was not the case (ps > .137). Results are available on request.

${ }^{8}$ As age and gender were not related to any of the measures (see Table 4), these variables were not considered further.

${ }^{9}$ Of the covariates, political orientation and national identification significantly and positively predicted autochthony beliefs, and education and PCC were significant negative predictors of opposition.
} 
Table 4. Partial and non-partial correlations for all measures, Study 2

\begin{tabular}{lccccc}
\hline & $M$ & $S D$ & 1 & 2 & 3 \\
\hline I. National nostalgia & 2.69 & 0.96 & - & $.40^{* * * *}$ & $.40^{* * * *}$ \\
2. Autochthony & 4.52 & 1.39 & $.32^{* * *}$ & - & $.47^{* * * *}$ \\
3. Opposition to Muslim expressive rights & 4.39 & 1.36 & $.30^{* * *}$ & $.41^{* * *}$ & - \\
Covariates & & & & & \\
4. Gender & - & - & .01 & -.06 & .07 \\
5. Age & 48.95 & 17.19 & .13 & .03 & -.04 \\
6. Education & 5.21 & 1.76 & $-.31^{* * *}$ & $-.18^{* *}$ & $-.39^{* * *}$ \\
7. Political orientation & 2.98 & 1.10 & .09 & $.19^{*}$ & $.19^{*}$ \\
8. National identification & 5.58 & 1.00 & $.26^{* * *}$ & $.26^{* * *}$ & $.20^{* *}$ \\
9. PCC & 5.16 & 0.97 & .10 & .13 & .04 \\
\hline
\end{tabular}

Note. The correlations between the three core constructs are presented above the diagonal and were calculated without controlling for the covariates.

$\mathrm{PCC}=$ perceived cultural continuity.

$* p<.05 ; * * p<.01 ; * * p<.001$.

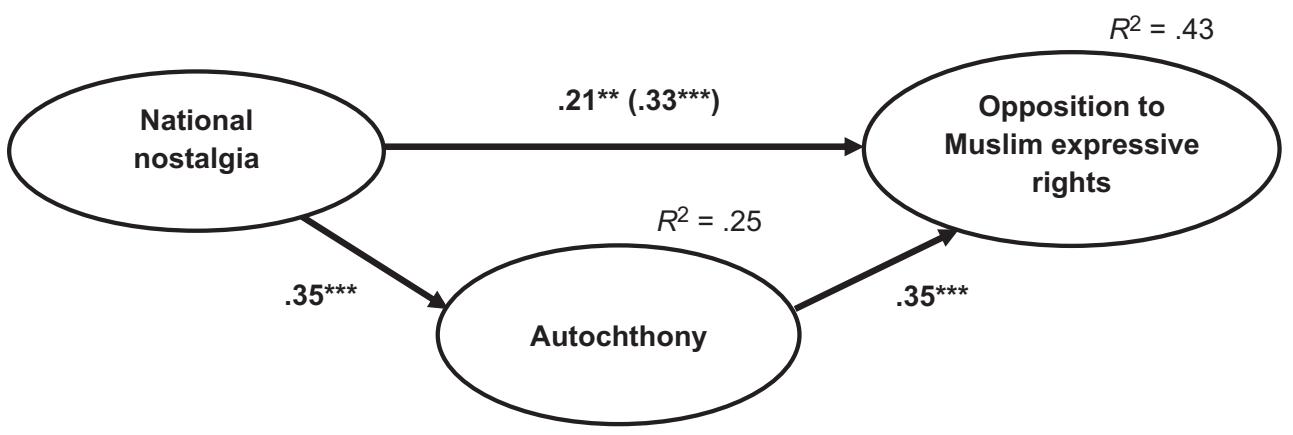

Figure 2. Structural equation model (Study 2): influence of national nostalgia on opposition to Muslim expressive rights, via autochthony (including, national identification, perceived cultural continuity, education, and political orientation as covariates). Note. Path coefficients are standardized estimates (marked in boldface), and the path coefficient in parenthesis reflects the total effect. $* * p<.01$; $* * * p<.00$ I. To simplify, indicators of latent variables are not shown. Model fit: $\chi^{2}(256)=379.68$, $p<.00 \mathrm{I} ; \mathrm{CFI}=.96, \mathrm{RMSEA}=.06$.

\section{STUDY 3}

The findings of Study 2 extend and replicate the results of Study 1 among a sample of the adult native Dutch population. Using a more general measure of national nostalgia, Study 2 shows that this concept can be empirically distinguished from both autochthony and opposition to Muslim rights, as well as from general positive feelings towards the nation (i.e. national identification) and other temporal understandings of national identity (i.e. PCC). Furthermore, the findings confirm the prediction that national nostalgia is related to more opposition to Muslim expressive rights via stronger endorsement of autochthony beliefs (while controlling for education, political orientation, and national identification). However, the results of Studies 1 and 2 are based on cross-sectional data and hence no causal conclusions can be drawn. Therefore, in Study 3 we used an experimental design in which national nostalgia was manipulated. 


\section{Method}

\section{Participants, design and procedure}

Participants were 67 students at Utrecht University who received 7 Euros for their participation. We excluded participants who indicated to be Muslim or non-Dutch, which resulted in a total sample of 59 participants ( $62.7 \%$ women). The ages ranged from 18 to 31 $(M=22.63, S D=3.26)$.

In the spring of 2013 , students were invited to the computer laboratory to participate in a study on current Dutch societal issues. This experiment was embedded in a bigger survey on cultural diversity beliefs, national identity and intergroup relations. A betweensubjects design was used, in which participants were randomly assigned to a national nostalgia or control condition. Participants completed all materials in an online version of the questionnaire in the order presented below. They were debriefed by e-mail after all the experimental sessions had finished.

In the national nostalgia condition, participants first watched a short movie ( $3 \mathrm{~min}$ ) about the Netherlands during the 1990s, which is the period in which the participants grew up. The movie showed typical Dutch things from this time period, such as the national coin the gilder (which was replaced by the Euro in 2002) and images of the last Eleven cities tour - a famous Dutch ice skating competition that has not been held anymore since $1997 . .^{10}$ The movie provided examples of national objects and events one can feel nostalgic about to facilitate the reading and writing task on national nostalgia that followed. This task was based on previous manipulations of personal nostalgia (see Iyer \& Jetten, 2011). Participants received and completed the following:

According to Van Dale dictionary 'nostalgia' means a sentimental longing for past. People sometimes sentimentally long for the Netherlands of the past: for those good old days. For instance, they long for the way Dutch society was and how daily life looked like. Do you sometimes long for the Netherlands of your past? Please bring to mind the good and nice things from the Netherlands of the past. Which things from the Dutch past evoke nostalgia in you? Please write down what you miss from the Netherlands of the past and how this makes you feel nostalgic.

Following previous research (e.g. Iyer \& Jetten, 2011) we designed a control condition that allowed us to differentiate the effect of national nostalgia from that of a more general reflection on the national past and from the mere salience of national identity. Specifically, in this control condition participants also watched a short movie of similar duration, showing a short overview of things that had happened in the Netherlands and had made the news in 2012. Similar to the national nostalgia condition, they then proceeded to a reading and writing task:

Please try to envisage an event that made the news last year and that involved the Netherlands. Try to think about this event as if you were an eye witness. Specifically, try to envisage this event as if you were a historian who wants to know all facts about national history. Please write about this event below as factual, neutral and detailed as possible.

\footnotetext{
${ }^{10}$ This movie was included in order to strengthen feelings of national nostalgia among the student sample that is rather young and for whom nostalgic feelings are not very salient in daily life, as shown in Study I.
} 


\section{Measures}

Except for national identification and the background characteristics, participants completed all measures on a 7-point scale ranging from 1 (strongly disagree) to 7 (strongly agree). We had two manipulation check items: 'I feel nostalgic when I think about the Netherlands of the past', and 'I long for the Netherlands of the past'. These two items were combined into a scale $(r=.55, p<.001)$. Autochthony was measured using the same 4 -item measure of Study $2(\alpha=.89)$. Opposition to Muslim rights was assessed with a 4 -item scale $(\alpha=.84)$. The items were similar to the ones used in Studies 1 and 2, and again reverse scored so that a higher value stands for more opposition. ${ }^{11} \mathrm{We}$ assessed the same background characteristics as in Study 1 (i.e. gender, age, and political orientation), measured national identification with the same single item as in Study 1, and assessed PCC with the same five items as in Study $2(\alpha=.75)$.

\section{Results}

\section{Manipulation check}

One-way ANOVA showed that there was a main effect of the national nostalgia manipulation on feelings of national nostalgia, $F(1,57)=3.84, p=.028, \eta_{\mathrm{p}}^{2}=.063$. Participants displayed higher feelings of national nostalgia in the national nostalgia condition $(M=4.18, S D=1.05)$ than in the control condition $(M=3.61, S D=1.16)$.

\section{Path model}

To examine our predictions we specified the path model in Figure 3. We tested this model (in AMOS 21.0) using manifest variables, ${ }^{12}$ and with political orientation, national identification, and PCC as covariates. ${ }^{13}$ The standardized paths and explained variance $\left(R^{2}\right)$ are shown in Figure 3. As expected, the national nostalgia manipulation (coded as $-1=$ control, 1 = nostalgia) exerted a significant positive effect on autochthony, which was subsequently related to stronger opposition. ${ }^{14}$ There was no significant direct effect of the manipulation on opposition, but analysis with bootstrapping procedures $(5,000$ samples) showed that the indirect effect via autochthony was significant $(\beta=.07,95 \%$ BCCI of .002-.206).

\section{Additional analyses}

We performed additional analyses to test whether the effect of the national nostalgia manipulation on autochthony was indeed driven by feelings of national nostalgia (i.e. the manipulation check), and not by other factors related to the manipulation. The reason is that, compared to the control condition, the national nostalgia manipulation referred to a more distant and positive national past. We therefore wanted to rule out the explanation that the effect of the nostalgia manipulation on autochthony is driven by perceptions of national identity continuity or general positive affect towards the

\footnotetext{
"I See footnote 5 .

${ }^{12}$ The sample size was too small to test a structural equation model with latent variables (Kline, 2005).

${ }^{13}$ Gender and age had no effects in any of the analyses and were therefore not considered further.

${ }^{14}$ Of the covariates in the path model, political orientation was positively related to both autochthony beliefs and opposition, and national identification was positively related to autochthony beliefs. PCC was not significantly related to either of the dependent variables in the path model.
} 


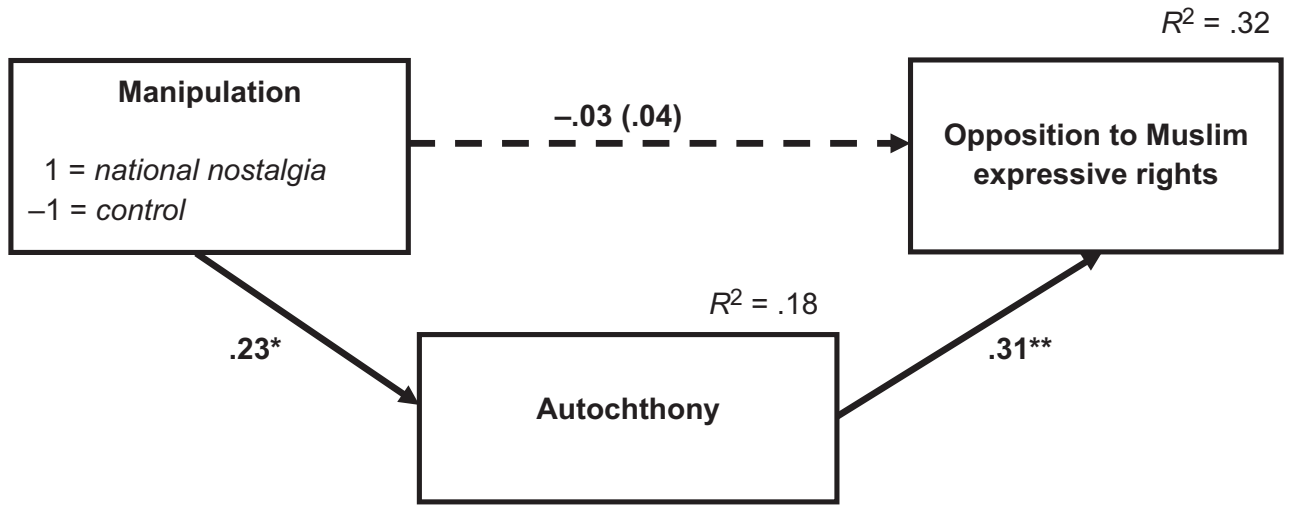

Figure 3. Path model (Study 3): influence of national nostalgia manipulation on opposition to Muslim expressive rights, via autochthony (including national identification, perceived cultural continuity, and political orientation as covariates). Note. Path coefficients are standardized estimates (marked in boldface), and the path coefficient in parenthesis reflects the total effect. Non-significant paths are shown as broken arrows. The model is saturated and hence the fit is perfect. ${ }^{*} p<.05 ; *^{*} p<.01$.

nation. We specified a new path model in which we tested whether the national nostalgia manipulation check, PCC, and national identification function as simultaneous mediators between the manipulation and autochthony beliefs. We found that the manipulation significantly predicted the manipulation check, $\beta=.25, p=.048$, but was not a significant predictor of PCC, $\beta=-.04, p=.786$, and national identification, $\beta=.15, p=.241$. The manipulation check and national identification significantly predicted autochthony $(\beta=.26, p=.031$, and $\beta=.26, p=.027$, respectively), and PCC had a marginally significant effect, $\beta=.21, p=.079$. These results indicate that only the manipulation check can function as a mediator between the manipulation and autochthony, and we found support for this indirect effect, $\beta=.09, p=.030$ (5,000 samples, 95\% BCCI of .007-.233). This indicates that feelings of national nostalgia were driving the effect of the national nostalgia manipulation on autochthony.

\section{STUDY 4}

The findings of Study 3 provide causal support for our prediction that national nostalgia enhances autochthony beliefs, which, in turn, are related to stronger opposition to Muslim expressive rights. In addition, we demonstrated that feelings of national nostalgia were driving the effect of the manipulation on autochthony beliefs rather than other factors that could be related to our manipulation, such as perceptions of national identity continuity and positive national affect. However, the results of Study 3 do not completely support the causality in our theoretical model, because they leave open the causal relationship between autochthony and opposition to Muslim rights. Therefore, in Study 4 autochthony was experimentally manipulated.

In the Netherlands, autochthony is an ideological discourse often used by far rightwing parties with relatively strong anti-immigrant views (Duyvendak, 2011; Martinovic \& Verkuyten, 2013). We therefore designed a manipulation that was rather subtle and factual, and that was not followed by manipulation checks explicitly assessing 
autochthony beliefs. In this way, we wanted to prevent people from guessing the true aim of the study and from showing counter reactions to the manipulation.

\title{
Method
}

\section{Participants, design and procedure}

This experimental study $(N=196)$ was conducted among a sample of the native Dutch population (36.7\% women) aged between 19 and 85 years $(M=51.83, S D=14.91)$. Participants received a questionnaire by means of an e-mail sent by a survey company (Thesistools.be), and were drawn from a panel of native Dutch respondents maintained by this company. In a between-subjects design, participants were randomly assigned to the autochthony or control condition. Participants in the autochthony condition read the following:

\begin{abstract}
The following questions are about 'autochthones' and 'allochthones'. These concepts are often used in the Netherlands and are derived from anthropology. The word 'autochthone' literally means 'from the same territory/soil'. In contrast, the term 'allochthone' literally means 'from a different territory/soil'. These definitions are used to make a distinction between people who arrived and settled first in a certain territory ('autochthones') and people who have arrived later from elsewhere ('allochthones').
\end{abstract}

In the control condition, participants did not receive a text and only completed the measures of interest.

\section{Measures}

Opposition to Muslim expressive rights was measured with the same four items as in Study $3(\alpha=.86)$. Measures for the covariates (age, gender, political orientation, education, and national identification $[\alpha=$.93]) were identical to Study 2 .

\section{Results}

We conducted structural equation modelling (in AMOS 21.0). To test our predictions, we created a dummy variable for the manipulation (coded as $1=$ autochthony, $-1=$ control) and latent variables for opposition to Muslim expressive rights and national identification. Political orientation, age, gender, and education were included as manifest control variables predicting opposition. The latent variable for national identification was also included as a predictor of opposition. ${ }^{15}$ The model had a good fit to the data, $\chi^{2}(53)=67.57, p=.086$; Comparative Fit Index $(\mathrm{CFI})=.99$, root mean square error of approximation (RMSEA) $=.04$, and explained $27 \%$ of the variance in opposition. The autochthony manipulation exerted a (marginally significant) positive effect on opposition, $\beta=.11, p=.053$ (1-tailed). ${ }^{16}$ This result provides preliminary support for the idea that the salience of autochthony increases opposition to Muslim expressive rights. ${ }^{17}$

\footnotetext{
${ }^{15}$ For the two latent variables, all standardized factor loadings were above .74 and cross-loadings were not allowed. In addition, we controlled for the correlations between the covariates in this model.

${ }^{16}$ None of the covariates significantly predicted opposition.

${ }^{17}$ We also examined whether the autochthony manipulation affected national identification, but this was not the case $(\beta=-.11, p=.129)$.
} 


\section{GENERAL DISCUSSION}

The key finding of the current research is that national nostalgia strengthens autochthony beliefs, which subsequently translate into more negative attitudes towards Muslim expressive rights. Whereas social psychological research has predominantly considered nostalgia as a positive emotion with positive consequences, the current findings indicate that feelings of national nostalgia can increase negative attitudes towards outgroups.

We examined national nostalgia as a specific type of group-based nostalgia. The findings of Study 1 provided support for our prediction that national nostalgia can be distinguished from personal nostalgia, and that only the former is a significant and positive predictor of anti-immigrant attitudes. Specifically, it was found that only national nostalgia positively predicted autochthony beliefs, which, in turn, related to more opposition to Muslim expressive rights. Studies 2 and 3 replicated this finding using a broader sample of the native Dutch population (Study 2), and by using an experimental design in which national nostalgia was manipulated (Study 3). Study 4 provided preliminary support for the second causal chain in our theoretical model, by showing experimentally that the salience of autochthony tended to (marginally significantly) increase opposition to Muslim expressive rights.

To our knowledge, this research provides the first demonstration of the potential negative effects of group-based nostalgia for intergroup relations. While there is quite some work on the consequences of nostalgia for personal functioning (e.g. Sedikides et al., 2008; Wildschut, Sedikides, Arndt, \& Routledge, 2006) the implications of nostalgia in intergroup settings remain largely unexplored (but see Turner et al., 2012, 2013). We examined the feelings of nostalgia that native majority members can experience on the basis of their national ingroup membership and how this affects attitudes towards immigrant outgroups. Following SCT (Turner et al., 1987) and theoretical and qualitative work on group-based nostalgia (Boym, 2001; Davis, 1979; Hewison, 1987; Milligan, 2003) we proposed that national nostalgia is likely to have negative consequences for the evaluation of immigrant outgroups, because it triggers a social categorization between old inhabitants of the country that are part of the shared national past (i.e. natives) and new inhabitants who arrived later and are not part of this past (i.e. immigrants). This social categorization was expected to activate ingroup representations that reaffirm and restore group boundaries between natives and immigrants. In line with this proposition, we showed that national nostalgia had negative consequences for the evaluation of expressive rights for Muslim immigrants, via a restoration of group boundaries on the basis of primo-occupancy and related entitlements (i.e. autochthony). By demonstrating the potential of group-based nostalgia to increase rather than reduce negative attitudes towards outgroups, these findings represent a theoretical advancement over previous research examining the role of nostalgia in relation to outgroup attitudes (Turner et al., 2012, 2013).

A related advancement of the present research is the introduction of autochthony as a mediator between national nostalgia and prejudice towards immigrants. Although the concept of autochthony has received much attention in anthropology (Ceuppens \& Geschiere, 2005; Gausset, Knrick, \& Gibb, 2011; Geschiere, 2009), it has been introduced into the social psychological literature only recently (see Martinovic \& Verkuyten, 2013). Moreover, whereas the concept of autochthony has been linked to feelings of group-based nostalgia in theoretical and ethnographic work (e.g. Duyvendak, 2011; Kasinitz \& Hillyard, 1995), this relationship has not received any quantitative empirical support. The 
findings of the present research highlight the importance of national nostalgia and autochthony beliefs for the social psychological study of intergroup relations.

\section{Limitations and directions for future research}

Notwithstanding the novel contributions of our work, there are several limitations that provide directions for future research. First, it is important to note that we examined national nostalgia and autochthony in the context of the Netherlands; a country characterized by quite strong negative sentiments towards Muslim immigrants (Gijsberts \& Lubbers, 2009; Sniderman \& Hagendoorn, 2007). This means that it is unclear whether our findings can be generalized to other contexts. Yet, as a comparable nostalgic discourse in relation to autochthony and immigration has been observed in both Western and nonWestern countries (Duyvendak, 2011; Geschiere, 2009), it is likely that similar mechanisms are at work in these national contexts.

Furthermore, it has been proposed that national nostalgia among Dutch natives has a strong restorative character (Duyvendak, 2011) whereby people longing for the good old days of the country also want to restore the way things were in the present (Boym, 2001). As national nostalgia was related to stronger endorsement of autochthony beliefs in all of the studies it is very likely that feelings of restorative nostalgia were involved. Yet, there may be other contexts in which national nostalgia takes on a more reflective form. People who experience reflective nostalgia consider the positive value of the (remembered) past for present purposes (Boym, 2001). That is, although they recognize that good things have been lost, they also see that much has been gained, and this experience might have different consequences for attitudes towards outgroups. Prospective work should examine both restorative and reflective forms of national nostalgia and their role in group dynamics.

A related point is that we did not assess the specific meanings that people attribute to national nostalgia. We only examined general feelings of national nostalgia in relation to outgroup attitudes, but it is likely that this relationship is dependent on how national nostalgia is defined. Following theoretical work we suggested that the likely reason why native Dutch' feelings of national nostalgia were related to opposition of Muslim expressive rights, is because their national nostalgia implies a combined sense of loss and longing for a (fondly remembered) national home of the past that was socially homogeneous and communal (Duyvendak, 2011; Rapport \& Dawson, 1998). However, there could be other social understandings of national nostalgia. For instance, while the Netherlands used to be seen as a tolerant country it has witnessed growing support for anti-immigrant parties during the last decades (Mudde, 2007). This development might make some natives feel nostalgic for the good old days when the country was less xenophobic and more open towards cultural diversity, which is likely to have different consequences for their evaluation of immigrant outgroups. Prospective work should examine different meanings of national nostalgia and their consequences for intergroup relations.

Another point that warrants discussion is that in Study 2 the effect of national nostalgia on opposition was only partially mediated by autochthony. This suggests that, next to autochthony, there are other processes that explain this effect. Historians, for example, have suggested that national nostalgia increases feelings of ingroup cohesiveness (e.g. Hewison, 1987), and future studies could examine whether this might be another explanation for why national nostalgia is related to stronger opposition to immigrant outgroups. A related point is that we only observed a significant indirect effect, and no 
total effect, of national nostalgia on opposition to Muslim rights in Studies 1 and 3, whereas we did find such a direct relation in Study 2. A possible reason for these different findings is that Studies 1 and 3 were based on student samples, who were younger and more strongly oriented towards the political left than our representative adult sample of the native Dutch population in Study 2. The students displayed relatively low feelings of national nostalgia and opposition to Muslim rights compared to the adults (see Tables 2 and 4), and his might explain why we only found an indirect effect via autochthony in these samples. Furthermore, a significant indirect effect in the absence of a total effect could indicate that, next to autochthony, there is another indirect path that carries the effect from national nostalgia to opposition to Muslim rights in the opposite direction (Hayes, 2009; MacKinnon, Krull, \& Lockwood, 2000). More specifically, whereas national nostalgia may have enhanced opposition to immigrants via endorsement of autochthony, reflecting on the good things of the national past may also have reduced outgroup opposition via, for example, more pro-social attitudes. This would be in line with research showing that nostalgia can foster a communal orientation (e.g. Wildschut et al., 2006). Future work should further explore how the effects of national nostalgia on outgroup evaluations can be explained.

We only found weak support for the idea that the salience of autochthony increased opposition to Muslim expressive rights in Study 4 . The effect size was small and only marginally significant using a one-tailed test. Therefore, this result provides more of a suggestion than conclusive evidence for the causal relationship between autochthony and opposition to Muslim rights. A potential explanation for the weak effect is that we used a rather subtle and factual manipulation of autochthony, because autochthony beliefs are strongly linked to current far right anti-immigrant discourses (Duyvendak, 2011; Geschiere, 2009; Martinovic \& Verkuyten, 2013), and we wanted to prevent participants from making this connection. For the same reason we also did not include manipulation checks. Yet, this means that it is unclear to what extent our manipulation actually activated autochthony beliefs and thereby increased opposition to Muslim expressive rights. Nevertheless, we speculate that the manipulation caused participants to think of themselves in terms of their native group membership, and also activated notions of ownership of the country and related entitlements. In the Netherlands, the terms 'autochthone' and 'allochthone' are not only official descriptive terms for distinguishing between people with and without a native background, but are also commonly used in Dutch public discourse to discuss group differences in entitlements and obligations (Duyvendak, 2011). Our manipulation might have activated the social categorization between autochthones versus allochthones, causing our native Dutch participants to categorize themselves in terms of their native group membership. Furthermore, research has shown that first arrival is a basis for inferring ownership of a territory and the related entitlements (Brown, Lawrence, \& Robinson, 2005; Friedman \& Ross, 2011; Verkuyten et al., 2014), and hence the participants in our experiment could have made similar inferences in relation the country on the basis of their primo-occupant status. While these results and speculations are inconclusive, they do provide a direction for prospective studies that could further develop autochthony manipulations, and test their effects on outgroup evaluations.

In conclusion, this research has implications for the understanding of intergroup relations in culturally diverse societies. We showed that native majority members who feel nostalgic for their national home of the past are more likely to endorse the belief that in being the primo-occupants of the country they are more entitled, which, in turn, fosters their opposition to rights for Muslims to publicly confirm and express their identity. As 
such, a political discourse that harbours this nostalgic sentiment among native populations could diminish the freedom for immigrant minorities to express their identities in the public space and could therefore lead to intergroup tensions and conflicts.

\section{References}

Arends-Tóth, J., \& Van de Vijver, F. J. R. (2003). Multiculturalism and acculturation: Views of Dutch and Turkish-Dutch. European Journal of Social Psychology, 33, 249-266. doi:10.1002/ejsp. 143

Avila, E. (2004). Popular culture in the age of white flight: Fear and fantasy in suburban Los Angeles. Berkeley, CA: University of California Press.

Batcho, K. I. (1995). Nostalgia: A psychological perspective. Perceptual and Motor Skills, 80, 131143. doi:10.2466/pms.1995.80.1.131

Batcho, K. I. (2013). Nostalgia: The bittersweet history of a psychological concept. History of Psychology, 13, 165-176. doi:10.1037/a0032427

Blumer, H. (1958). Race prejudice as a sense of group position. The Pacific Sociological Review, 1, 3-7. doi:10.2307/1388607

Boym, S. (2001). The future of nostalgia. New York, NY: Basic Books.

Branscombe, N. R., \& Doosje, B. (2004). Collective guilt: International perspectives. Cambridge, UK: Cambridge University Press.

Brown, G., Lawrence, T. B., \& Robinson, S. L. (2005). Territoriality in organizations. Academy of Management Review, 30, 577-594. doi:10.2307/20159145

Ceuppens, B., \& Geschiere, P. (2005). Autochthony: Local or global? New modes in the struggle over citizenship and belonging in Africa and Europe. Annual Review of Anthropology, 34, 385-407. doi:10.1146/annurev.anthro.34.081804.120354

Davis, F. (1979). Yearning for yesterday: A sociology of nostalgia. New York, NY: The Free Press.

Duyvendak, J. (2011). The politics of home: Belonging and nostalgia in Western Europe and the United States. Ballingstoke, UK: Palgrave.

Friedman, O. (2008). First possession: An assumption guiding inferences about who owns what. Psychonomic Bulletin \& Review, 15, 290-295. doi:10.3758/PBR.15.2.290

Friedman, O., \& Ross, H. (2011). Twenty-one reasons to care about the psychological basis of ownership. New Directions for Child and Adolescent Development, 132, 1-8. doi:10.1002/cd. 292

Gausset, Q., Knrick, J., \& Gibb, R. (2011). Indigeneity and autochthony: A couple of false twins? Social Anthropology, 19, 135-142. doi:10.1111/j.1469-8676.2011.00144.x

Geschiere, P. (2009). The perils of belonging: Autochtbony, citizenship, and exclusion in Africa and Europe. Chicago, IL: University of Chicago Press.

Gijsberts, M., \& Lubbers, M. (2009). Wederzijdse beeldvorming [Mutual image creation]. In M. Gijsberts \& J. Dagevos (Eds.), Jaarrapport Integratie 2009 [Annual Report Integration 2009] (pp. 254-291). The Hague, the Netherlands: Netherlands Institute for Social Research.

Hayes, A. F. (2009). Beyond Baron and Kenny: Statistical mediation analysis in the new millennium. Communication Monographs, 76, 408-420. doi:10.1080/03637750903310360

Hewison, R. (1987). The beritage industry: Britain in a climate of decline. Sussex, UK: Methuen. Iyer, A., \& Jetten, J. (2011). What's left behind: Identity continuity moderates the effect of nostalgia on well-being and life choices. Journal of Personality and Social Psychology, 101, 94-108. doi: $10.1037 / \mathrm{a} 0022496$

Jost, J. T. (2006). The end of the end of ideology. American Psychologist, 61, 651-670. doi:10.1037/ 0003-066X.61.7.651

Kasinitz, P., \& Hillyard, D. (1995). The old timer's tale: The politics of nostalgia on the waterfront. Journal of Contemporary Ethnography, 24, 139-164. doi:10.1177/089124195024002001

Kline, R. B. (2005). Principles and practice of structural equation modelling. New York, NY: The Guilford Press. 
Mackie, D. M., Devos, T., \& Smith, E. R. (2000). Intergroup emotions: Explaining offensive action tendencies in an intergroup context. Journal of Personality and Social Psychology, 79, 602616. doi:10.10371/0022-3514.79.4.602

MacKinnon, D. P., Krull, J. L., \& Lockwood, C. M. (2000). Equivalence of the mediation, confounding and suppression effect. Prevention Science, 1, 173-182. doi:10.1023/A:1026595011371

Martinovic, B., \& Verkuyten, M. (2013). 'We were here first, so we determine the rules of the game': Autochthony and prejudice towards out-groups. European Journal of Social Psychology, 43, 637-647. doi:10.1002/ejsp. 1980

Milligan, M. J. (2003). Displacement and identity discontinuity: The role of nostalgia in establishing new identity categories. Symbolic Interactionism, 26, 381-403. doi:10.1525/si.2003.26.3.381

Mudde, C. (2007). Populist radical right parties in Europe. Cambridge, UK: Cambridge University Press.

Rapport, N., \& Dawson, A. (1998). Migrants of identity: Perceptions of bome in a world of movement. Oxford, UK: Berg.

Routledge, C., Arndt, J., Sedikides, C., \& Wildschut, T. (2008). A blast from the past: The terror management function of nostalgia. Journal of Experimental Social Psychology, 44, 132-140. doi:10.1016/j.jesp.2006.11.001

Sani, F., Bowe, M., Herrera, M., Manna, C., Cossa, T., Miao, X., \& Zhou, Y. (2007). Perceived collective continuity: Seeing groups as entities that move through time. European Journal of Social Psychology, 37, 1118-1134. doi:10.1002/ejsp.430

Sedikides, C., Wildschut, T., Arndt, J., \& Routledge, C. (2008). Nostalgia: Past, present, and future. Current Directions in Psychological Science, 17, 304-307. doi:10.1111/j.1467-8721.2008. 00595.x

Smeekes, A., Verkuyten, M., \& Poppe, E. (2011). Mobilising opposition towards Muslim immigrants: National identification and the representation of national history. British Journal of Social Psychology, 50, 265-280. doi:10.1348/014466610X516235

Smeekes, A., Verkuyten, M., \& Poppe, E. (2012). How a tolerant past affects the present: Historical tolerance and the acceptance of Muslim expressive rights. Personality and Social Psychology Bulletin, 38, 1410-1423. doi:10.1177/0146167212450920

Sniderman, P. M., \& Hagendoorn, L. (2007). When ways of life collide: Multiculturalism and its discontents in the Netherlands. Princeton, NJ: Princeton University Press.

Turner, J. C., Hogg, M. A., Oakes, P. J., Reicher, S. D., \& Wetherell, M. S. (1987). Rediscovering the social group: A self-categorization theory. Oxford, UK: Blackwell.

Turner, R. N., Wildschut, T., \& Sedikides, C. (2012). Dropping the weight stigma: Nostalgia improves attitudes toward persons who are overweight. Journal of Experimental Social Psychology, 41, 58-64. doi:10.1016/j.jesp.2011.09.007

Turner, R. N., Wildschut, T., Sedikides, C., \& Gheorghiu, M. (2013). Combating the mental health stigma with nostalgia. European Journal of Social Psychology, 43, 413-422. doi:10.1002/ejsp.1952

Verkuyten, M., Sierksma, J., \& Thijs, J. (2014). First arrival and owning the land: How children reason about ownership of territory. Journal of Environmental Psychology, 41, 58-64.

Verplanken, B. (2012). When bittersweet turns sour: Adverse effects of nostalgia on habitual worriers. European Journal of Social Psychology, 42, 285-289. doi:10.1002/ejsp.1852

Wildschut, T., Bruder, M., Robertson, S., Tilburg, W. A. P., \& Sedikides, C. (2014). Collective nostalgia: A group-level emotion that confers unique benefits on the group. Journal of Personality and Social Psychology, 107, 844-863. doi:10.1037/a0037760

Wildschut, T., Sedikides, C., Arndt, J., \& Routledge, C. (2006). Nostalgia: Content, triggers, functions. Journal of Personality and Social Psychology, 91, 975-993. doi:10.1037/0022-3514. 91.5.975

Zhao, X., Lynch, Jr, J. G., \& Chen, Q. (2010). Reconsidering Baron and Kenny: Myths and truths about mediation analysis. Journal of Consumer Research, 37, 197-206. doi:10.1086/651257 